\title{
UNDERSTANDING DIGITAL TRANSFORMATION FOR FUTURE PROJECT MANAGEMENT: A REVIEW AND FRAMEWORK
}

Marcel Fernandes Dallaqua (marcel.dallaqua@usp.br) - Escola Politécnica, Universidade de São Paulo (EP-USP).

Samuel Laiber Bonadiman (samuelbonadiman@usp.br) - Escola Politécnica, Universidade de São Paulo (EP-USP).

Fábio Pires (abiopires@usp.br) - Escola Politécnica, Universidade de São Paulo (EP-USP).

Marly Monteiro de Carvalho (파lymc@usp.br) - Escola Politécnica, Universidade de São Paulo (EPUSP).

\begin{abstract}
The rising of digital technologies holds potential implications to disrupt many organizations' domains at different levels of analysis. However, the literature on project management (PM) still lacks research on this important phenomenon. Therefore, this study aims to investigate how digital transformation (DT) influences future PM. An in-depth literature review employed bibliometric, network, and content analyses, applying VOSviewer, UNICET and NVivo 11 software. Results show, first, that the application of intelligent artifacts for PM activities dominates the still incipient literature. Second, that artifacts proposed mainly aim at improving PM quality area. And third, that the main artifacts encountered are intelligent methods, e.g., algorithms and practices. Gap exploration and future research recommendations are also observed.
\end{abstract}

Keywords: Digital transformation, Project management, Industry 4.0, Intelligent systems, Internet of things 


\section{INTRODUCTION}

The rising of digital transformation has the potential to disrupt many domains of the organisation looking to succeed in the future digital world (McAfee and Brynjolfsson, 2017). Digital transformation is rapidly becoming quite common (Corea, 2019; Ganis and Waszkiewicz, 2018) and goes beyond organisations, bringing profound changes in society and industries through digital technologies (Majchrzak et al., 2016), helping individuals to make decisions in their daily lives (McDaniel, 2018; Ganis and Waszkiewicz, 2018).

The body of knowledge has increased our understanding of digital transformation and the core SMACIT technologies (social, mobile, analytics, cloud, and Internet of things) (Sebastian et al., 2017), but also of platforms and blockchain (Vial, 2019). However, organisations still struggle to gain transformational effects and realize this new phenomenon (Fitzgerald et al., 2014).

The digital transformation phenomena affect business models and has an impact on PM (Ganis and Waszkiewicz, 2018). It impacts several management domains and systems of management. Project managers need to coordinate multidisciplinary knowledge, must adapt to new technologies and learn how to deal with them in the project context. Other challenges for project managers are filtering and capturing the right information and communicating effectively with stakeholders during the project lifecycle. To be successful, 21st century project managers must deal with constant changes in the PM environment (Seymour and Hussein, 2014) through networks in different cultures and countries that challenge effective communication, forcing project managers to adapt organizational structure changes.

Thus, people will interact more in the future, leading to the question of what influence Industry 4.0 will have in the work environment (Marnewick and Marnewick, 2019) in general and for project managers specifically (Seymour and Hussein, 2014; Marnewick and Marnewick, 2019). The changes in the project environment encompass: (1) multidisciplinary knowledge must be acquired and disseminated; (2) continuous adaptations to new technologies, looking for the best possible technical solution for the project; (3) organizational structure and culture will change, and project managers need to adapt (Cho, 2009; Marnewick and Marnewick, 2019); (4) uncertainties, interruptions and constant changes will be part of 
the life of a project manager and will need to find a way to control them (Saunders et al., 2016; Marnewick and Marnewick, 2019).

However, literature lacks a comprehensive portrait of its implications in temporary organizations, particularly in this COVID-19 pandemic period with the acceleration of the virtuality and digitization of project work that reinforces this research agenda (Mueller and Klein, 2020). Although many speculate about the impact of digital transformation upon PM work context, the extant literature lacks an in-depth understanding of the implications in PM context (Albogamy and Dawood, 2015; Hammad, Abbasi, and Ryan, 2016; Panova and Hilletofth, 2018; Strojny and Jedrusik, 2018; Koseoglu and Nurtan-Gunes 2018; Golizadeh et al., 2019; Niu, Anumba and Lu, 2019; Emblemsvåg, 2020).

In this scenario, the objective of this article is to answer the following questions: How will the digital transformation influence future PM (RQ1)? Which project knowledge areas are more affected by digital transformation (RQ2)? And what are the main gaps and key topics for a future research agenda for project management's digital transformation (RQ3)?

This paper presents a systematic literature review (SLR) combining bibliometrics, network, and content analysis, applying VOSViewer, UCINET and NVivo software to address its research questions. The sampling process was conducted in Scopus and Web of Sciences databases. This study contributes in two folds: (a) it discusses and proposes a definition for "digital project management" and (b) it presents a framework for "digital project management".

The next section will present the literature review on digital transformation. Then, Section 3 presents the research design detailing the literature review research protocol. Section 4 presents the research results and analyses. Finally, sections 5 and 6 discuss and conclude this research contributions and limitations.

\section{LITERATURE REVIEW}

Digital transformation (DT) means the disruptive implications of digital technologies for businesses, encompassing new business models, new types of products and services, new 
types of customer experiences (Nambisan et al., 2019) that distinguishes from previous IT transformations in terms of combinations of technologies, velocity, and its holistic nature (Vial, 2019). DT can alter the value creation paths in terms of value proposition, value network, digital channels, agility, and ambidexterity but also causes structural changes in organizational culture and structure, leadership, employee roles, and skills (Vial, 2019).

DT primarily relates to organizations (Vial, 2019) and has been associated with the term Industry 4.0, which "comprises a variety of technologies to enable the development of a digital and automated manufacturing environment as well as the digitisation of the value chain" and "can be described as the increasing digitisation and automation of the manufacturing environment as well as the creation of a digital value chain to enable the communication between products and their environment and business partners" (Oesterreich and Teuteberg, 2016).

In the Industry 4.0, humans "are expected to do less physical but more mental work", to face "the challenge to collaborate with or manage more autonomous systems", and to "work in fully integrated environments that are optimized for maximum efficiency, while their tasks will be influenced by decentralized decision making" (Beier et al., 2020). And organizations will need to "become decentralized and flexible, in order to being able to quickly adapt to frequently changing customer requirements" and their business processes "to be integrated and to allow for more service-orientation while still being very efficient" (Beier et al., 2020). In short, "Industry 4.0 has been considered a new industrial stage in which several emerging technologies are converging to provide digital solutions" (Frank, Dalenogare, and Ayala, 2019).

The digital technologies frequently associated with DT refer to technologies related to social, mobile, analytics, cloud, and the internet of things, the so-called SMACIT acronym (Sebastian et al., 2017). However, in a recent literature review, Vial (2019) also found blockchain, platforms \& ecosystem, but less frequently. For Frank et al. (2019), digital base technologies as SMACIT are embedded in front-end technologies in four blocks: smart supply chain, smart working, smart manufacturing, and smart products. PM is, as seen, neglected. 
The emergence of such a diverse set of digital technologies, digital platforms, and digital infrastructures has transformed innovation in significant ways at different levels of analysis (individual, organization, ecosystem/community, regional/societal) (Nambisan et al., 2019). For Kane et al. (2017), notably, the organizational culture and structure enable digital maturity through a "supportive culture that embraces collaboration, risk-taking, and experimentation". Their research "reveals that a flexible mindset combined with a networked and team-based organizational structure supports an organization's ability to react to digital trends and become more digitally mature".

To illustrate, DT in construction projects has been pulled by Building Information Modeling (BIM) implementation that embedded the digital technologies such as cyber-physical infrastructure, horizontal and vertical integration, cloud systems, and augmented reality (Koseoglu et al., 2019). Thus, BIM allows the digital representation of information on the physical structure, collaboration, and project management, leading to numerous activities associated with design, engineering, project management, and delivery during a construction project's life cycle (Holzer, 2016).

\section{RESEARCH METHODS}

To reach this research goal, the systematic literature review method was adopted and carried out in two major processes: sampling and data analysis (Carvalho et al., 2013). These processes and their seven steps are described in figure 1.

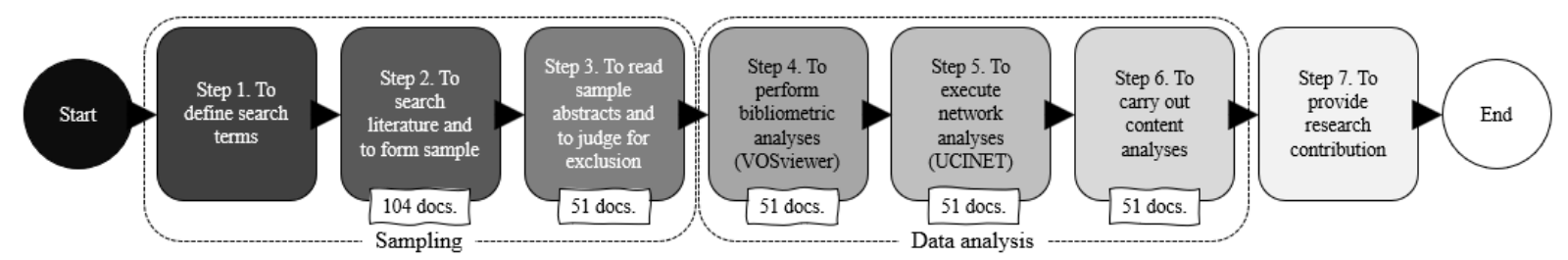

FIGURE 1 - Systematic review process

Sampling process was carried out in three steps. The first step aimed at defining the search string. The second and third steps aimed at forming the sample of documents to be reviewed. 
In step one, an initial search string was generated randomly. Then, Scopus database was used to search for related terms. "Documents" were searched through "Keywords" field in an iterative way until terms' saturation was reached. Two iterations (A and B) were needed. In iteration A, 13,537 documents were found. Filters were not applied. The most frequent 160 keywords were assessed. Eleven new terms were included. And the search string was updated. In iteration B, 227,326 documents were found. Again, filters were not applied and the most frequent 160 keywords were assessed. Any new terms were included, meaning saturation was reached. Then, search strings were defined. Table 1 sums up iterations A and B until saturation.

TABLE 1 - String set definition

\begin{tabular}{|c|c|c|c|}
\hline Iteration & Initial string & Final string & $\begin{array}{l}\text { Terms } \\
\text { included }\end{array}$ \\
\hline $\mathrm{A}$ & $\begin{array}{c}\text { "4.0" OR "digital transformation" OR } \\
\text { "digital twin*" }\end{array}$ & $\begin{array}{l}\text { "4.0" OR "digital transformation" OR } \\
\text { "digital twin" " OR "cps*" OR "cyber } \\
\text { physical system" OR "cyber-physical } \\
\text { system*" OR "digitalization" OR } \\
\text { "digitalisation" OR "digitization" OR } \\
\text { "digitisation" OR "iiot" OR "intelligent } \\
\text { system*" OR "internet of thing " OR } \\
\text { "iot" }\end{array}$ & +11 \\
\hline B & $\begin{array}{l}\text { "4.0" OR "digital transformation" OR } \\
\text { "digital twin*" OR "cps*" OR "cyber } \\
\text { physical system*" OR "cyber-physical } \\
\text { system*" OR "digitalization" OR } \\
\text { "digitalisation" OR "digitization" OR } \\
\text { "digitisation" OR "iiot" OR "intelligent } \\
\text { system*" OR "internet of thing*" OR } \\
\text { "iot" }\end{array}$ & $\begin{array}{l}\text { "4.0" OR "digital transformation" OR } \\
\text { "digital twin*" OR "cps*" OR "cyber } \\
\text { physical system*" OR "cyber-physical } \\
\text { system*" OR "digitalization" OR } \\
\text { "digitalisation" OR "digitization" OR } \\
\text { "digitisation" OR "iiot" OR "intelligent } \\
\text { system*" OR "internet of thing*" OR } \\
\text { "iot" }\end{array}$ & $\begin{array}{l}0 \text { (saturation } \\
\text { reached) }\end{array}$ \\
\hline
\end{tabular}

To finish step one, words defined after iterations A and B (see table 2) were associated to the term "Project management" through the logical operator "AND", highlighting the crossfertilization approach employed in this review, and resulting in the following: "Project management" AND ("4.0" OR "digital transformation" OR "digital twin*" OR "cps*" OR "cyber physical system*" OR "cyber-physical system*" OR "digitalization" OR “digitalisation" OR "digitization" OR “digitisation” OR "iiot" OR "intelligent system*" OR "internet of thing*" OR "iot"). Sample documents resided in the intersection (I) illustrated in figure 2 . 


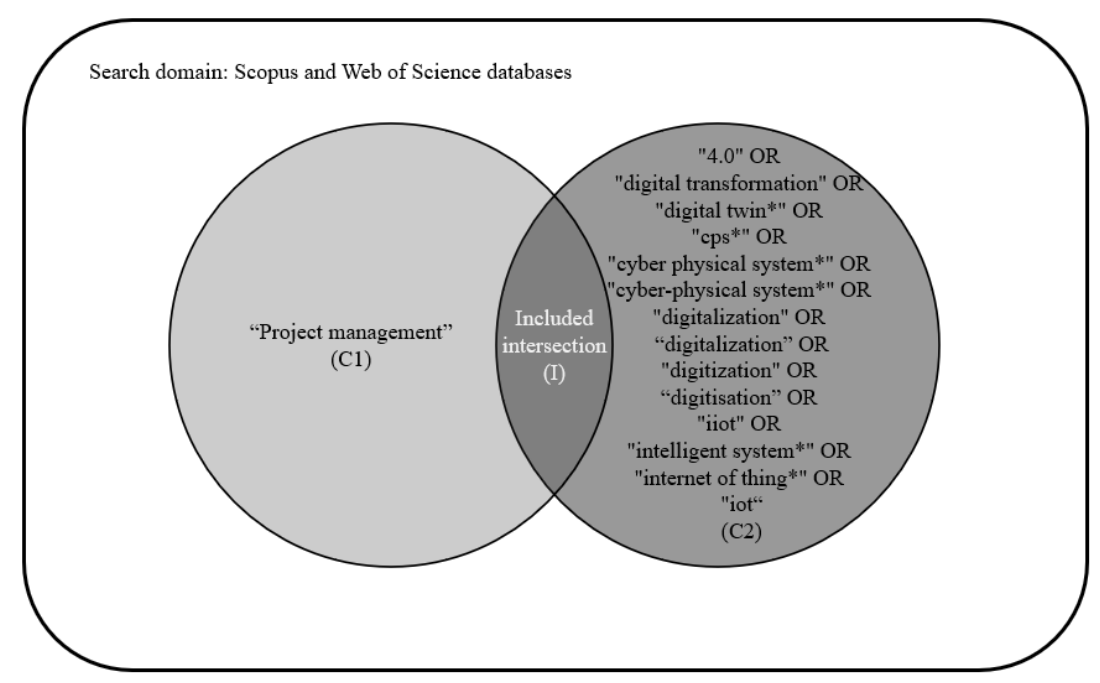

FIGURE 2 - Venn diagram

In step two, both Scopus and Web of Science databases were employed to search for research documents. On Scopus, "Documents" were searched in "Article title, Abstract, Keywords". 1,210 documents were initially found before filters. Document type filters "Article" and "Review", and subject area filter "Business, Management and Accounting" were applied. 91 documents were, then, exported. On Web of Science, "Basic Search" was carried out in "Topic". 355 results were initially obtained from "Web of Science Core Collection" before filters. Document type filters "Article", "Early Access" and "Review", and category filters "Management", “Operations Research Management Science”, and "Business" were applied. 24 documents were, then, exported. Finally, 11 duplicated documents were excluded, and 104 were selected to form initial sample. Figure 3 illustrates sampling process step 2.

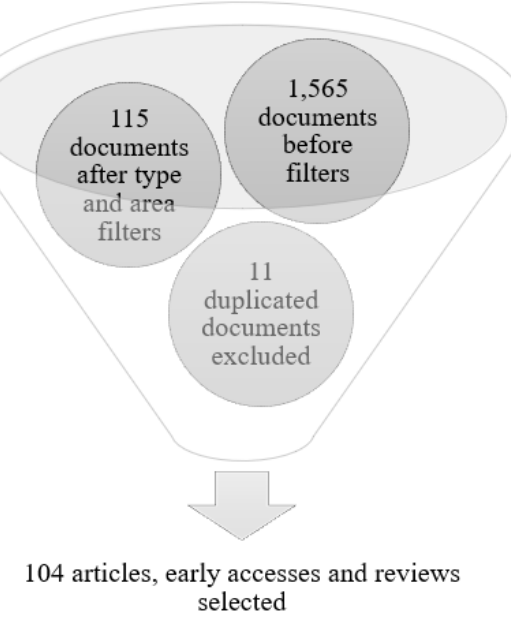




\section{FIGURE 3 - Starting sample}

In step 3, all 104 titles, abstracts, and keywords were read. Authors, then, decided to keep each document in the sample or to exclude it, based on this research goal. Finally, 51 out of the 104 documents were included in the final sample. Table 2 categorizes the 104 sample documents in six groups and helps to justify inclusion and exclusion criteria to form final sample.

TABLE 2 - Decision criteria

\begin{tabular}{|c|c|c|c|}
\hline Group & Reason & Decision & Counting \\
\hline $\begin{array}{l}\text { 1. Intelligent artifacts for } \\
\text { project management }\end{array}$ & $\begin{array}{c}\text { Papers in this group propose artifacts, i.e., constructs, } \\
\text { models, methods, and systems, for executing project } \\
\text { management }\end{array}$ & Included & 51 \\
\hline $\begin{array}{l}\text { 2. Project management or } \\
\text { digitalization not or barely } \\
\text { addressed }\end{array}$ & $\begin{array}{l}\text { Papers in this group barely or do not address circle } \\
\text { C1 or circle C2 (see figure } 2 \text { ) }\end{array}$ & Excluded & 26 \\
\hline $\begin{array}{l}\text { 3. Managing digitalization } \\
\text { projects }\end{array}$ & $\begin{array}{l}\text { Papers in this group discuss how to manage projects } \\
\text { for circle } \mathrm{C} 2 \text { (see figure } 2 \text { ) }\end{array}$ & Excluded & 17 \\
\hline $\begin{array}{l}\text { 4. Digitalization demands } \\
\text { project management }\end{array}$ & $\begin{array}{l}\text { Papers in this group highlight the importance of } \\
\text { project management for circle C2 (see figure } 2 \text { ), e.g., } \\
\text { project management skills, PMOs, etc. }\end{array}$ & Excluded & 5 \\
\hline $\begin{array}{l}\text { 5. Digital capabilities for } \\
\text { project management }\end{array}$ & $\begin{array}{c}\text { Papers in this group highlight the importance of } \\
\text { circle C2 for circle C1 (see figure 2), e.g., digital } \\
\text { capabilities }\end{array}$ & Excluded & 1 \\
\hline $\begin{array}{l}\text { 6. Full or part of paper not } \\
\text { available }\end{array}$ & $\begin{array}{l}\text { Papers are not available or present missing } \\
\text { information }\end{array}$ & Excluded & 4 \\
\hline \multicolumn{3}{|c|}{ Total } & 104 \\
\hline
\end{tabular}

After completing the sampling process, data analyses were carried out in the additional steps, i.e., bibliometric analysis, network analysis, and content analysis, with the help of three different software. In step four, bibliometric analyses involved demographics, keywords' cooccurrence, and authors' co-citation. Bibliometric analyses were conducted with the help of VOSviewer. In step five, network analysis comprehended mapping the most relevant works into nodes and their relationships within each other within a network. Network analysis was carried out with the support of UCINET. In step six, content analyses involved coding 
structures and extraction of relevant information and insights from the sample, thus exploring, proposing, hypothesizing, and building knowledge. Content analyses were conducted with the use of NVivo 11.

Three coding schemes were, then, employed to perform content analysis. Out of them, one is a standard, traditional coding scheme from systematic literature reviews, i.e., kind of study (KS). Another is an important coding schemes from the project management literature, i.e., project management knowledge areas (KA) (PMI, 2017). And a third is an important coding scheme coming from information systems literature, i.e., front-end technologies for digital project management (DPM) (Hevner et al., 2004). Coding is presented in detail in the next section.

\section{RESULTS}

This section is divided in the three topics: bibliometrics, network and content analyses.

\subsection{Bibliometric analysis}

In step four, bibliometric analyses were performed within the sample documents. three analyses were performed, i.e., demographics, keywords co-occurrence, and authors' cocitation. Demographics showed three main results. First, studies on intelligent systems applied to project management practice are recent, since: 32 studies (63\%) have been published within the last 5 years, and 43 documents (84\%) have been published within the last 10 years. Second, there is not a strong reference in the field, since: 120 authors (93\%) have published only 1 document each, and the 2 authors who publish the most have only 3 publications each. And third, three main journals stood out, even though multiple journals have been interested in the field since: 23 journals ( $88 \%$ ) have up to 2 publications each; the International Journal of Project Management publishes twice as studies as the average of published studies per journal of the sample, i.e., 4 against 1.96; the Engineering, Construction and Architectural Management journal, 8 against 1.96; and the Journal of Construction Engineering and Management, 11 against 1.96. In other words, demographics shows that intelligent systems applied to project management is a relatively recent field that awakes the interest of 3 important journals from the project management and construction fields mainly. 
Keywords co-occurrence analysis demonstrated four important clusters, i.e., yellow, red, blue, and green. The yellow cluster comprehends studies that propose artifacts manly to the monitoring and controlling tasks of project management. The red cluster brings together documents from the construction contexts, involving mainly discussions on the building information modelling artifacts. The blue clusters studies that propose intelligent artifacts, e.g., neural networks, for risk analyses in the project management context. And the green cluster groups studies that propose intelligent systems mainly to decision making on investments perspectives. Figure 4 presents the keywords co-occurrence map generated in VOSviewer.

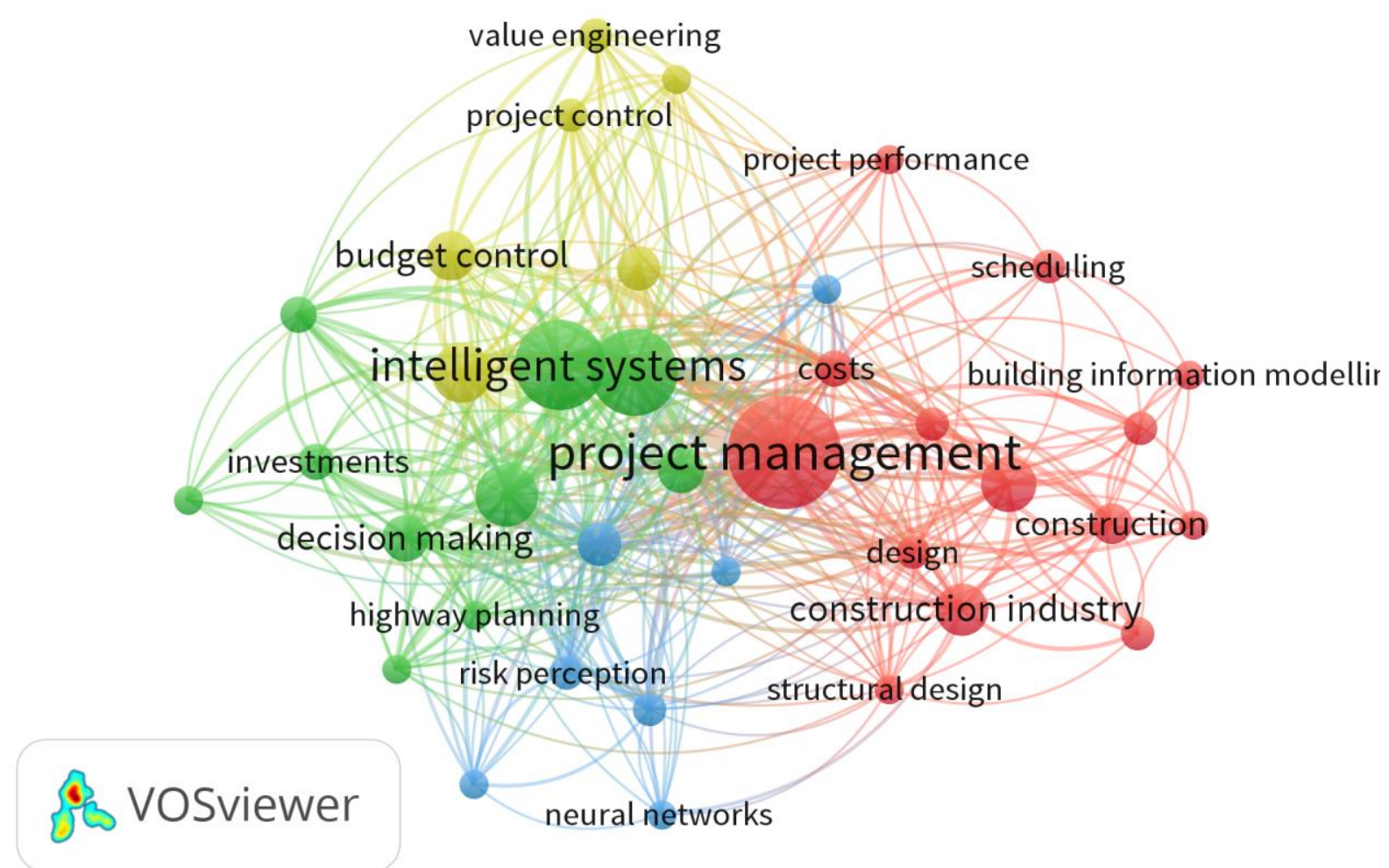

FIGURE 4 - Keyword's co-occurrence map

Note: Figure 4 resulted from creating a map based on bibliographic data by reading data from bibliographic data files, with the following configuration: co-occurrence (type of analysis), all keywords (unit of analysis), full counting (counting method), 3 (threshold), and 37 (keywords to be selected). 
To conclude step four, cited references co-citation analysis showed a main cluster comprehending main references that focus specifically on artifacts for PM scheduling and PM buffer management. Figure 5 presents the references co-citation map generated in VOSviewer.

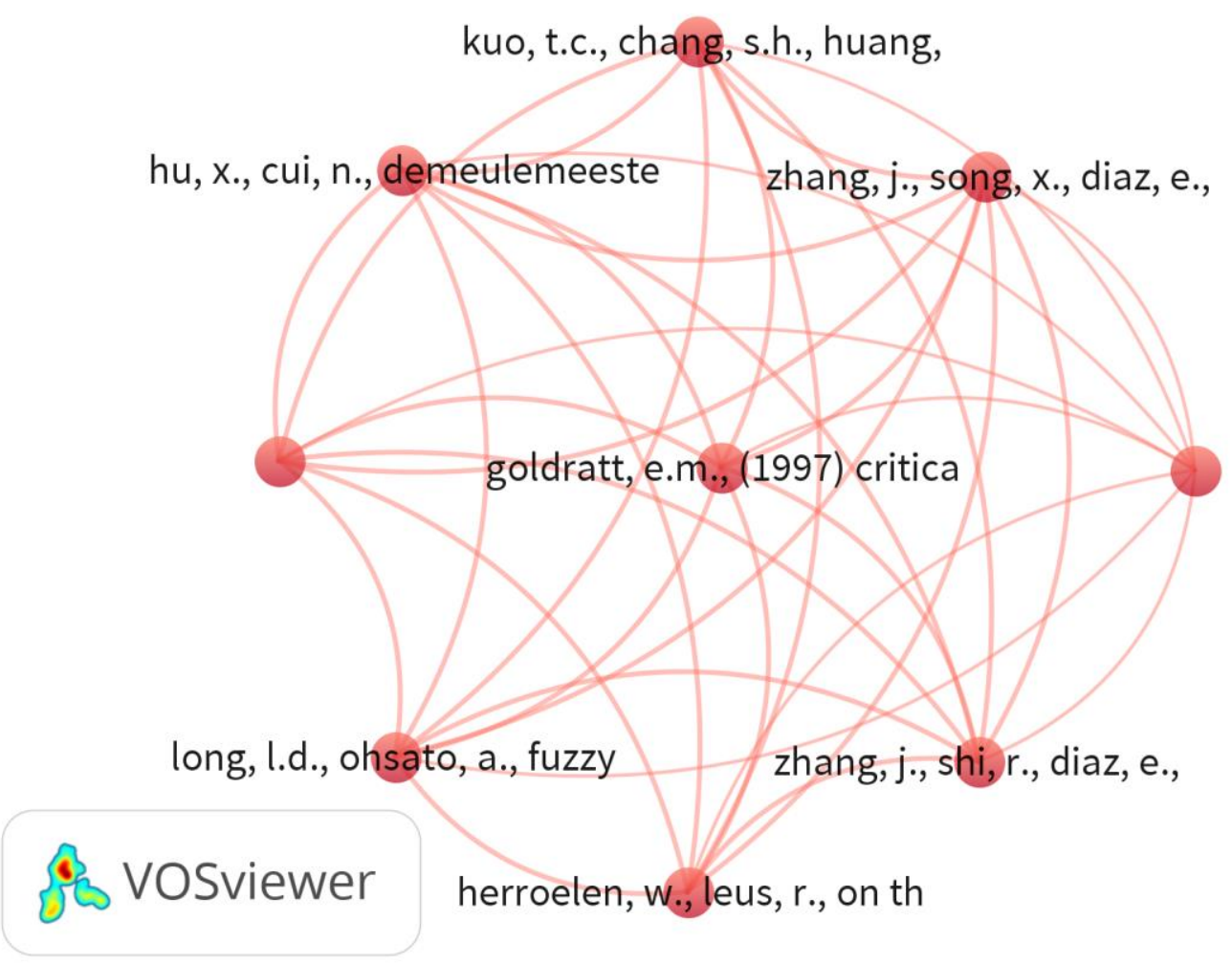

FIGURE 5 - Reference's co-citation map

Note: Figure 5 resulted from creating a map based on bibliographic data by reading data from bibliographic data files, with the following configuration: co-citation (type of analysis), cited references (unit of analysis), full counting (counting method), 2 (threshold), and 16 (references to be selected). Section 4.2 presents the network analysis results.

\subsection{Network analysis}

In step five, network analysis was executed, and three important results could be highlighted. First, 38 documents (75\%) presented themselves completely isolated. Second, 5 isolated groups were identified, say: group [4-12-52], group [19-27], group [31-53], group [9-10], and group [8-13-26-47] (see figure 6). Group [4-12-52] works with the Earned Value 
Management (EVM) methodology for project duration monitoring. Group [19-27] proposes artifacts for capital projects and public-private partnerships (PPP). Group [31-53] studies the application of the Internet of Things (IoT) to construction project management. Group [9-10] discusses the application of the Cyber Physical Systems (CPS) to construction project management. And, finally, group [8-13-26-47] proposes artifacts for risk management in the context of projects. And third, the absence of relevant central nodes in figure 6 (due to a high degree of isolation in the network) may be an indicative of a lack of influential or significant works within the literature sample analyzed. For instance, network centrality measures (e.g., degree connectivity, closeness, betweenness, and prestige centralities) cannot be even significantly calculated in this specific "network." Figure 6 presents the network generated in UNICET.
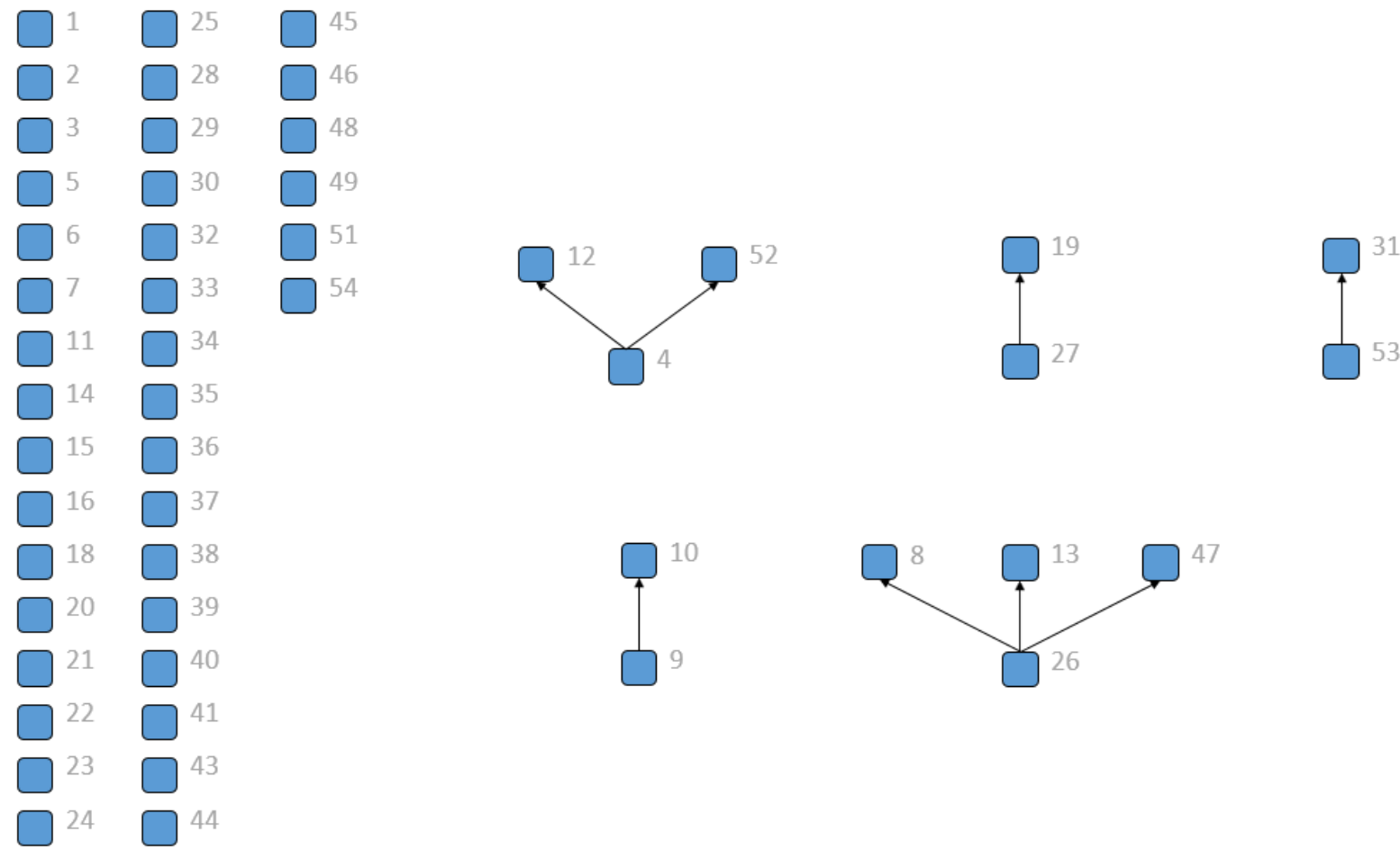

FIGURE 6 - Network

Figure 6 presents the network generated in UCINET with this research 51 sample documents. Section 4.3 presents the results for this work content analysis. 


\subsection{Content analysis}

In step six, content analyses were carried out looking for providing answers to this research questions. The 51 sample documents were, then, classified accordingly to the coding structures. Table 3 presents such classification.

TABLE 3 - Codified documents

\begin{tabular}{|c|c|c|c|c|}
\hline \multirow[b]{2}{*}{ ID } & \multirow[b]{2}{*}{ Work } & \multicolumn{3}{|c|}{ Coding structure } \\
\hline & & $\mathrm{KA}$ & DPM & KS \\
\hline 1 & Hammad et al. (2016) & KA4 & DPM3 & $\mathrm{KS} 3|\mathrm{KS} 1| \mathrm{KS} 6$ \\
\hline 2 & Haller et al. (2015) & KA5 & DPM2 & KS1 | KS4 \\
\hline 3 & Martinez-Rojas et al. (2016) & KA.5 & DPM4 & KS1|RS6 \\
\hline 4 & Votto et al. $(2020)$ & KA3 & DPM3 & KS1 $\mid$ KS6 $\mid$ KS4 \\
\hline 5 & Sun and Zhang (2015) & KA4 & DPM13 & KS1 $\mid$ KS6 6 KS4 \\
\hline 6 & Firouzi and Khayyeti (2020) & KA3 & DPM13 & KS1 $\mid$ KS6 $\mid$ KS4 \\
\hline 7 & Bosch-Sjitsema and Gluch (2019) & KA5 & DPM1 & KS6 \\
\hline 8 & Salzh and Moselhi (2015) & KA4 & DPM3 & KS1|KS6 \\
\hline 9 & Jiang et al. $(2020)$ & KA.5 & DPM4 & KS1|KS6 \\
\hline 10 & Akanmu and Anumba (2015) & KA5 & DPM4 & KS1|KS6 \\
\hline 11 & $\begin{array}{l}\text { Belaid (2011) } \\
\end{array}$ & KA9 & DPM4 & KS1 $\mid$ KS6 $\mid$ KS4 \\
\hline 12 & Hammad et al. (2018) & RA3 & DPM3 & KS1|KS6 \\
\hline 13 & Albogamy and Dawood (2015) & KA9 & DPM3 & KS3 |KS5|KS1|KS6 \\
\hline 14 & Gamis and Waszkiewicz (2018) & KAS & DPM4 & KS6 \\
\hline 15 & Mazouzk et al (2019) & KA5 & DPM4 & KS7 $\mid$ KS5 $\mid$ KS1 $\mid$ KS5 \\
\hline 16 & Ksewuurven and Lian (2019) & KA.5 & DPM4 & KS1 \\
\hline 18 & Matthies and Coners (2018) & KA5 & DPM3 & KS1 $\mid$ KS6 \\
\hline 19 & Alasad and Motawa (2015) & RAg & DPM2 & KS5 $\mid$ KS6 $\mid$ KS1 $\mid$ KS6 $\mid$ KS4 \\
\hline 20 & Zhang, Jia, and Diaz (2018) & KA4 & DPM3 & KS1 $\mid$ KS6 $\mid$ KS4 \\
\hline 21 & Batselier and Vanhoucke (2015) & KA5 & DPM3 & KS6|KS4 \\
\hline 22 & Chang et al (2018) & KA4 & DPM4 & KS1 $\mid \mathrm{KS} 6$ \\
\hline 23 & Eke et al (2019) & KA9 & DPM3 & KS6 | KS4 | KS1 | KS6 \\
\hline 24 & Yoon and Yu (2019) & KA3 & DPM2 & KS5 $\mid$ KS6 $\mid$ KS $4 \mid$ KS1 $\mid$ KS 6 \\
\hline 25 & Le et al. $(2020)$ & KA5 & DPM3 & KS1 $|\mathrm{KS} 6| \mathrm{KS} 4$ \\
\hline 26 & Lee $(2019)$ & RA5 & DPM3 & \begin{tabular}{|l|l|l|l|} 
KS1 & KS6 & KS4 \\
\end{tabular} \\
\hline 27 & Du et al. (2019) & KAS & DPM2 & \begin{tabular}{ll|l|} 
KS8 & KS6 & KS4 \\
\end{tabular} \\
\hline 28 & Niebecker et al (2008) & KA5 & DPM3 & KS1|KS6 \\
\hline 29 & Liu et al (2017) & KA9 & DPM3 & KS1 $\mid$ KS6 $\mid$ KS4 \\
\hline 30 & Zhang and Wan (2019) & KA3 & DPM3 & KS1 $\mid$ KS6 $\mid$ KS4 \\
\hline 31 & Ghimire et al. (2017) & KA9 & DPM4 & KS1 | KS6 \\
\hline 32 & Kayis et al. (2007) & RA5 & DPM4 & KS6 $\mid$ KS1 $1 \mid$ KS6 \\
\hline 33 & Golly et al. (2008) & KA5 & DPM3 & KS1 | KS6 \\
\hline 34 & Marques et al (2017) & KA5 & DPM3 & KS6|KS1|KS6 \\
\hline 35 & Penova and Hilletofth (2018) & KA9 & DPM3 & KS3 | KS4 | KS1 \\
\hline 36 & Koseoglu and Nurtan-Gunes (2018) & KA5 & DPM4 & KS6|KS3 \\
\hline 37 & Andalib et al. (2018) & KA9 & DPM3 & KS1|KS6 \\
\hline 38 & Moselhi et al (1991) & KA.5 & DPM3 & KS1 \\
\hline 39 & Chang and $\mathrm{K}_{0}$ (2017) & KA9 & DPM3 & KS1|KS6 \\
\hline 40 & Vanhoucke et al (2001) & KA5 & DPM3 & KS1|KS6 \\
\hline 41 & Emblemswág $(2020)$ & KA5 & DPM2 & KS3 $\mid$ KS1 \\
\hline 43 & Georgy et al. (2005) & KA5 & DPM4 & KS5 $\mid$ KS1 $1 \mid$ KS6 \\
\hline 44 & Shahrara et al. (2017) & KA9 & DPM3 & KS6|KS1 \\
\hline 45 & Tran and Molenaar (2015) & KA9 & DPM3 & KS1 | KS6 \\
\hline 46 & Zhang et al. (2020) & KA.5 & DPM3 & KS1 $|\mathrm{KS} 6| \mathrm{KS} 4$ \\
\hline 47 & Okmen and Oztas (2015) & KA4 & DPM3 & KS4 \\
\hline 48 & Golizadeh et al (2019) & KA5 & DPM4 & KS3 \\
\hline 49 & Harvey (2004) & KA2 & DPM3 & KS2 \\
\hline 51 & Strojny and Jedruaik (2018) & KA10 & DPM3 & KS3 |KS1 |KS6 \\
\hline 52 & Acebes et al. (2015) & KAO & DPM3 & KS1 $\mid$ KS4 \\
\hline 53 & Niu et al. (2019) & KA5 & DPM1 & KS3 $\mid$ KS6 $\mid$ KS7 $\mid$ KS1 \\
\hline 54 & Smith (1992) & KA.5 & DPM4 & KS1 \\
\hline
\end{tabular}


From table 3, three important results may be observed. First, analysis in code KA showed that the articles are mainly aimed at the areas of knowledge Quality (47\%), followed by the areas of Risk (24\%), Cost (12\%), Time (10\%), Communication (4\%), Stakeholder (2\%) and Scope (2\%). The other areas of knowledge did not appear in the classification. Second, analysis in code DPM showed that literature mainly discusses or proposes methods for PM, i.e., algorithms and practices (59\%), followed by: instantiations, i.e., implemented and prototype systems (27\%); models, i.e., abstractions and representations (10\%); and constructs, i.e., vocabulary and symbols. And third, most of the studies (84\%) employ a multi-method approach, frequently designing and evaluating artifacts for PM. In short, it was observed that all articles present tools, methods and simulations that assist in the performance of the different phases of a project's life cycle and do not necessarily present a technological base involved (IoT, Cloud, Big Data, Analytics), or discuss a success dimension for projects (Carvalho and Rabechini, 2015). Section 5 presents this work discussion and claimed main contribution.

Also, there were only eight related works that review the literature on "digitalisation" or "industry 4.0", and "project management" concomitantly. However, all of them present different objectives and, therefore, limited scopes. In other words, they are limited to a specific: (a) project management knowledge area, e.g., risk (Albogamy and Dawood, 2015; Panova and Hilletofth , 2018), cost (Hammad, Abbasi, and Ryan, 2016), stakeholder management (Strojny and Jedrusik, 2018), or quality (Emblemsvåg, 2020); (b) project management context, e.g., construction (Koseoglu and Nurtan-Gunes 2018; Panova and Hilletofth, 2018; Golizadeh et al., 2019); or (c) technology, e.g., Building Information Modelling (Koseoglu and Nurtan-Gunes 2018), Remoted Piloted Aircrafts (Golizadeh et al., 2019), Internet of Things, Cyber-Physical Systems, or Smart Construction Objects (Niu, Anumba and Lu, 2019). Albogamy and Dawood (2015), for instance, review the literature to "design an effective risk assessment methodology". Panova and Hilletofth (2018), in their turn, carry out their review aiming at investigating "models and methods for managing supply chain risks and delays in construction". Hammad, Abbasi, and Ryan (2016) execute another literature review to introduce "a new methodology to estimate and allocate cost contingency during the planning phase, as well as managing cost contingency during the execution phase". Strojny and Jedrusik (2018), also as an example, perform a review "to identify the basic methodological assumptions of the process of stakeholder analysis" in project management. 
Emblemsvåg (2020), in addition, produce a review paper with the goal of discussing some of the critical aspects of project-based industries concerning quality management and particularly Quality 4.0”. Koseoglu and Nurtan-Gunes (2018), through another review, aim to define "interactions between BIM [Building Information Modelling] process and lean". Golizadeh et al. (2019) also review the literature, but to assess RPA (Remoted Piloted Aircrafts) systems in the construction industry. Finally, Niu, Anumba, and Lu (2019) work on a review to propose "a deployment framework that integrates IoT [Internet of Things], CPS [Cyber-Physical Systems], and SCOs [Smart Construction Objects]". This way, there is a need for a (systematic and holistic) literature review on "digitalisation" in the project management field, that is not limited to any specific project management context, nor to any specific project management knowledge area, nor to a specific technology.

\section{DISCUSSION}

Five main points for discussion stood out from section 4. First, in terms of KA, it is observed a strong tendency in research towards project management quality, i.e., $47 \%$ of the reviewed documents are dedicated to quality, as mentioned before. Therefore, this work suggests that future research could focus on the application of intelligent artifacts to other PMKA to develop research in a more balanced way. Figure 7 illustrates this recommendation.
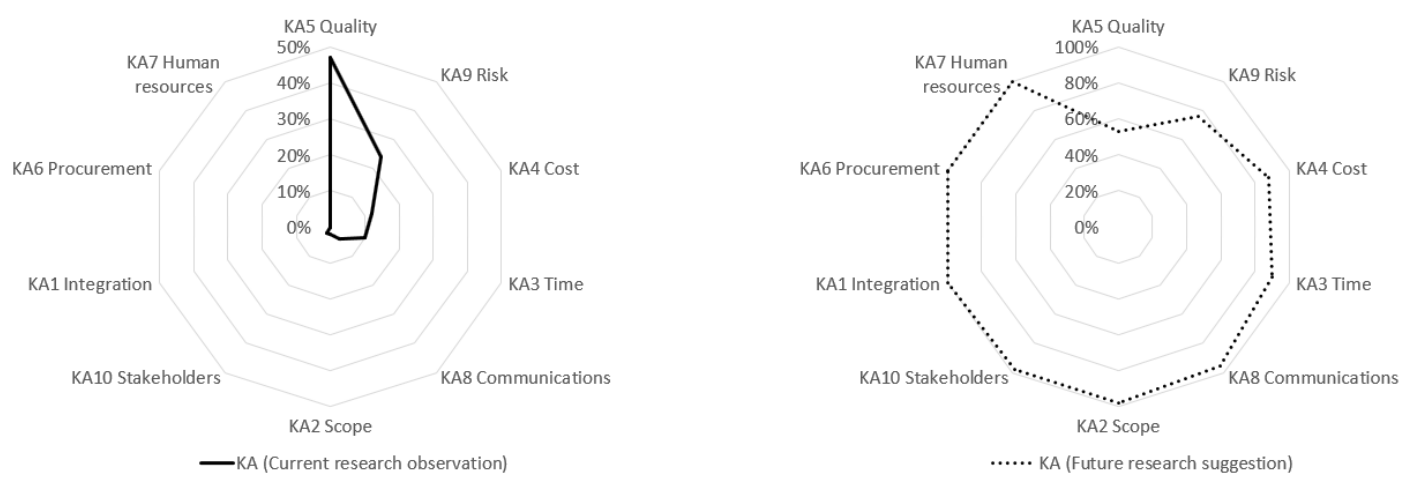

FIGURE 7 - Future research recommendation based on KA

Second, in terms of DPM, it is observed a strong tendency in research towards digital project management methods, i.e., 59\% of the reviewed documents are dedicated to discussing or proposing intelligent methods, as also mentioned before. Therefore, this work suggests that future research could focus on the development of other DPM artifacts to develop research in 
a more robust way, i.e., focus on constructs and their relationships. Figure 8 illustrates this recommendation.

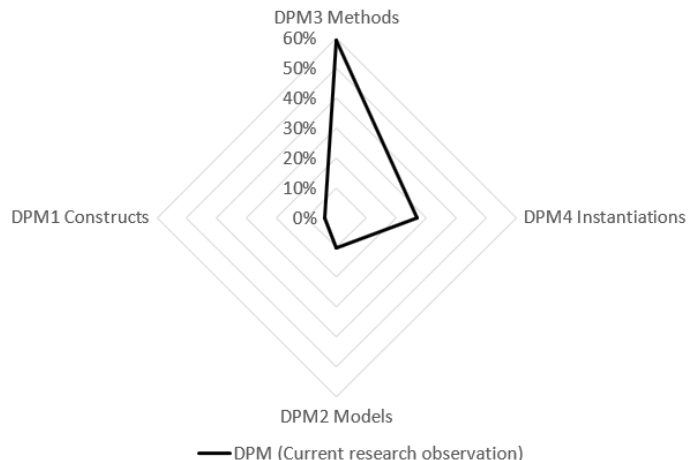

—DPM (Current research observation)

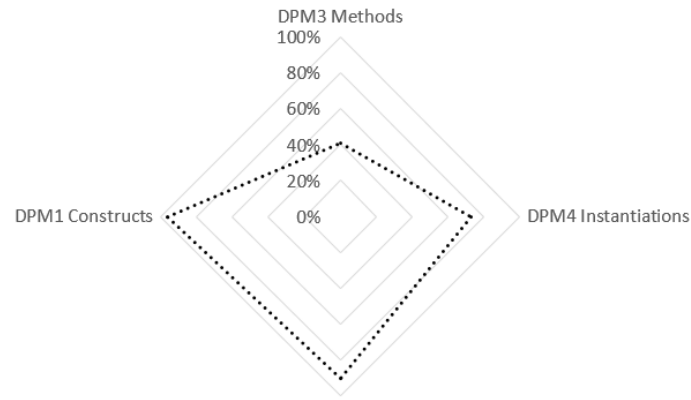

DPM2 Models

….. DPM (Future research suggestion)

FIGURE 8 - Future research recommendation based on DPM artifacts

Third, in terms of KS, it is observed, first, a strong tendency multi-methods approach, i.e., 48 documents (84\%) employ a multi-method approach, being modelling (34\%) and case study (36\%) methods the most frequent ones. Thus, it is highlighted the way literature authors like to work. Any future research suggestion is presented here.

Fourth, according to the sample of articles analyzed in this research, a definition for the term "digital project management" can be proposed: the application of intelligent artifacts, i.e., constructs, models, methods, or instantiations, to project management discipline. Figure 9 presents a first framework based on the just proposed definition. 


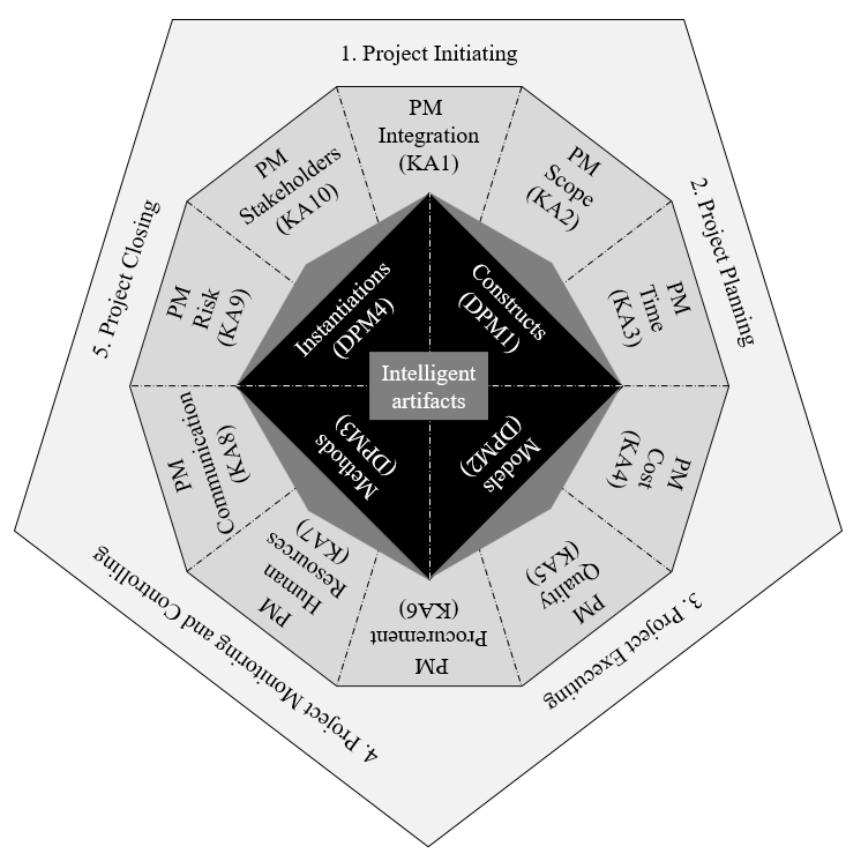

FIGURE 9 - Digital project management

And fifth, finally, a contribution to an important and existing framework from the industry 4.0 (Frank, Dalenogare, and Ayala, 2019) can also be suggested here. Figure 10 presents a second framework contribution, because of this literature review, concluding step seven.

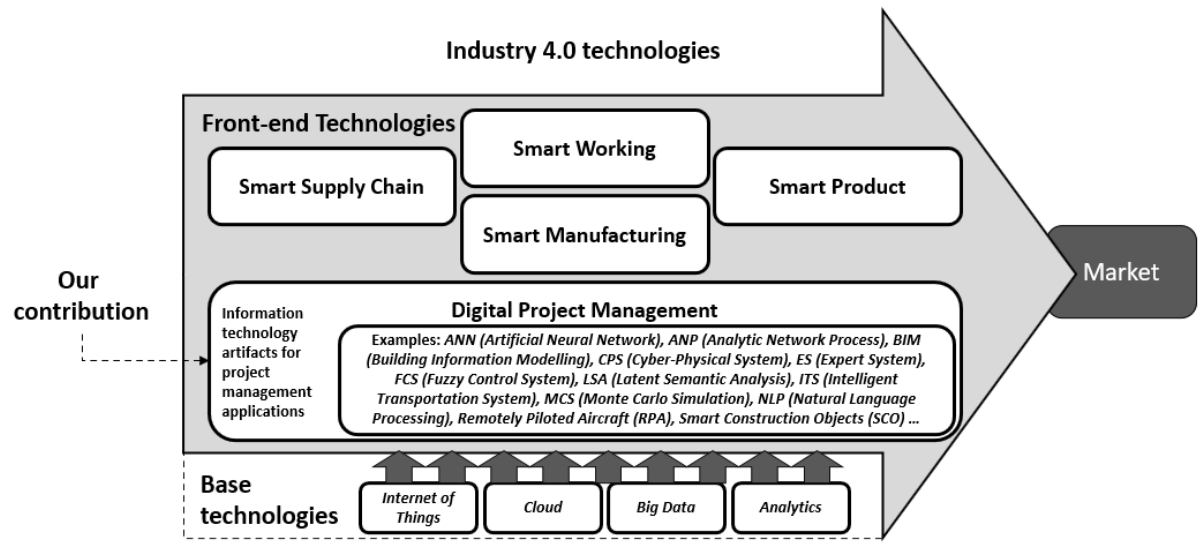

FIGURE 10 - Digital project management in the Industry 4.0 context (see Frank et al., 2019) 


\section{CONCLUSION}

A systematic literature review on project management and digital transformation has been presented in the last pages (see figure 1). Multiple analyses have been conducted (see sections 4.1, 4.2, and 4.3), and a more structured view of this literature has been pictured (see table 5). Structured suggestions for future research have been made (see figures 7 and 8). And, finally, a definition for digital project management is proposed in line with two framework contribution (see figures 9 and 10).

This research main limitation is imposed by a manual and subjective process to remove documents from the research sample, thus reducing the systematic characteristic of this review and the ability to reproduce it (see table 2). This limitation is, however, a setback from the iterative process implemented to include as many related terms as needed (see table 1). In other words, authors have chosen carefully to read all related titles, abstracts, and keywords, as opposed to incurring the risk of leaving one or more important search term(s) out.

Other limitations can also be pointed out, such as: (i) the need for previous and more substantial discussion on global virtual teams, digital technologies, BIM and how they impact PM. It could enrich discussion proposed in chapter five. (ii) The need to include new terms in table 1, such as artificial intelligence and blockchain. They could enrich initial sample. (iii) The need to enrich coding structure, e.g., including codes from Frank et al. (2019). It could provide different perspectives, thus, richer content analysis. (iv) The need to discuss VOSViewer maps deeper. It could provide new avenues for future research. (v) The need for a more detailed and less statistically descriptive content analysis. It could enrich and make this work more robust. (vi) To deepen the discussion with previous literature. It could enrich concluding remarks. (vii) The eventual need to clarify the origin of the contributions proposed, i.e., definition and framework. And, (viii) the need to build the sample with a snowballing technique.

\section{REFERENCES}

Acebes, F., Pereda, M., Poza, D., Pajares, J. and Galán, J.M., 2015. Stochastic earned value analysis using Monte Carlo simulation and statistical learning techniques. International Journal of Project Management, 33(7), pp.1597-1609. [ID 52]

Akanmu, A. and Anumba, C.J., 2015. Cyber-physical systems integration of building information models and the physical construction. Engineering, Construction and Architectural Management. [ID 10] 
Alasad, R. and Motawa, I., 2015. Dynamic demand risk assessment for toll road projects. Construction management and economics, 33(10), pp.799-817. [ID 19]

Albogamy, A. and Dawood, N., 2015. Development of a client-based risk management methodology for the early design stage of construction processes: applied to the KSA. Engineering, Construction and Architectural Management. [ID 13]

Andalib, M.S., Tavakolan, M. and Gatmiri, B., 2018. Modeling managerial behavior in real options valuation for project-based environments. International Journal of Project Management, 36(4), pp.600-611. [ID 37]

Batselier, J. and Vanhoucke, M., 2015. Empirical evaluation of earned value management forecasting accuracy for time and cost. Journal of Construction Engineering and Management, 141(11), p.05015010. [ID 21]

Beier, G., Ullrich, A., Niehoff, S., Reißig, M. and Habich, M., 2020. Industry 4.0: How it is defined from a sociotechnical perspective and how much sustainability it includes-A literature review. Journal of cleaner production, p.120856.

Belaid, F., 2011. Decision-making process for project portfolio management. International Journal of Services Operations and Informatics, 6(1-2), pp.160-181. [ID 11]

Bosch-Sijtsema, P. and Gluch, P., 2019. Challenging construction project management institutions: the role and agency of BIM actors. International Journal of Construction Management, pp.1-11. [ID 7]

Carvalho, M.M., Fleury, A., and Lopes, A.P., 2013. An overview of the literature on technology roadmapping (TRM): Contributions and trends. Technological Forecasting and Social Change, 80(7), pp.1418-1437.

Carvalho, M.M. and Rabechini Junior, R., 2015. Impact of risk management on project performance: the importance of soft skills. International Journal of Production Research, 53(2), pp.321-340.

Chang, C.Y. and Ko, J.W., 2017. New approach to estimating the standard deviations of lognormal cost variables in the Monte Carlo analysis of construction risks. Journal of Construction Engineering and Management, 143(1), p.06016006. [ID 39]

Chang, Y.C., Shih, C.W. and Hsu, W.L., 2017. Entailment-based intelligent system for software project monitoring and control. IEEE Systems Journal, 12(1), pp.216-227. [ID 22]

Cho, L., 2009, August. Adopting an Agile Culture: A User Experience Team's Journey. In 2009 Agile Conference (pp. 416-421). IEEE.

Corea, F., 2019. Applied artificial intelligence: Where AI can be used in business (Vol. 1). Springer International Publishing.

Du, J., Zhao, D. and Zhang, O., 2019. Impacts of human communication network topology on group optimism bias in Capital Project Planning: a human-subject experiment. Construction Management and Economics, 37(1), pp.44-60. [ID 27]

Eke, G., Elgy, J. and Wedawatta, G., 2019. Establishing a link between contractor selection strategy and project outcomes: Simulation study. Journal of Construction Engineering and Management, 145(10), p.04019062. [ID 23]

Emblemsvåg, J., 2020. On Quality 4.0 in project-based industries. The TQM Journal. [ID 41]

Firouzi, A. and Khayyati, M., 2020. Bayesian Updating of Copula-Based Probabilistic Project-Duration Model. Journal of Construction Engineering and Management, 146(5), p.04020046. [ID 6]

Fitzgerald, M., Kruschwitz, N., Bonnet, D., Welch, M. 2014. Embracing digital technology: a new strategic imperative. MIT Sloan Management Review, 55 (2), 1-12

Frank, A.G., Dalenogare, L.S. and Ayala, N.F., 2019. Industry 4.0 technologies: Implementation patterns in manufacturing companies. International Journal of Production Economics, 210, pp.15-26.

Ganis, M.R. and Waszkiewicz, M., 2018. Digital Communication Tools as a Success Factor of Interdisciplinary Projects. Problemy Zarzadzania, 16. [ID 14]

Georgy, M.E., Chang, L.M. and Zhang, L., 2005. Prediction of engineering performance: a neurofuzzy approach. Journal of Construction Engineering and Management, 131(5), pp.548-557. [ID 43] 
Ghimire, S., Luis-Ferreira, F., Nodehi, T. and Jardim-Goncalves, R., 2017. IoT based situational awareness framework for real-time project management. International Journal of Computer Integrated Manufacturing, 30(1), pp.74-83. [ID 31]

Golizadeh, H., Hosseini, M.R., Martek, I., Edwards, D., Gheisari, M., Banihashemi, S. and Zhang, J., 2019. Scientometric analysis of research on "remotely piloted aircraft". Engineering, Construction and Architectural Management. [ID 48]

Golly, T., De Barros, A.G. and Falls, L.C., 2008. ITS applications for work zones. Journal of Advanced Transportation, 42(1), pp. 65-93. [ID 33]

Haller, M., Lu, W., Stehn, L. and Jansson, G., 2015. An indicator for superfluous iteration in offsite building design processes. Architectural Engineering and Design Management, 11(5), pp.360-375. [ID 2]

Hammad, M.W., Abbasi, A. and Ryan, M.J., 2016. Allocation and management of cost contingency in projects. Journal of management in engineering, 32(6), p.04016014. [ID 1]

Hammad, M.W., Abbasi, A. and Ryan, M.J., 2018. Developing a novel framework to manage schedule contingency using theory of constraints and earned schedule method. Journal of Construction Engineering and Management, 144(4), p.04018011. [ID 12]

Harvey, J., 2004. Scope projects in 10 steps. Quality progress, 37(8), p.64. [ID 49]

Hevner, A.R., March, S.T., Park, J. and Ram, S., 2004. Design science in information systems research. MIS quarterly, pp.75-105.

Holzer, D. The BIM Manager's Handbook: Guiadance for Professionals in Architecture, Engineering, and Construction, 1st ed.;Wiley: West Sussex, UK, 2016; ISBN 978-1-118-98231-0.

Jiang, W., Ding, L. and Zhou, C., 2020. Cyber physical system for safety management in smart construction site. Engineering, Construction and Architectural Management. [ID 9]

Kaewunruen, S. and Lian, Q., 2019. Digital twin aided sustainability-based lifecycle management for railway turnout systems. Journal of Cleaner Production, 228, pp.1537-1551. [ID 16]

Kane, G.C., Palmer, D., Phillips, A.N., Kiron, D., and Buckley N., “Achieving Digital Maturity” MIT Sloan Management Review and Deloitte University Press, July 2017. https://www.the-digital-insurer.com/wpcontent/uploads/2017/11/1105-59180-MITSMR-Deloitte-Digital-Report-2017.pdf

Kayis, B., Zhou, M., Savci, S., Khoo, Y.B., Ahmed, A., Kusumo, R. and Rispler, A., 2007. IRMASdevelopment of a risk management tool for collaborative multi-site, multi-partner new product development projects. Journal of Manufacturing Technology Management. [ID 32]

Koseoglu, O. and Nurtan-Gunes, E.T., 2018. Mobile BIM implementation and lean interaction on construction site. Engineering, Construction and Architectural Management. [ID 36]

Koseoglu, O.; Keskin, B.; Ozorhon, B. 2019. Challenges and Enablers in BIM-Enabled Digital Transformation in Mega Projects: The Istanbul New Airport Project Case Study. Buildings 9 (5), 115.

Le, C., Jeong, H.D., Le, T. and Kang, Y., 2020. Evaluating Contractors' Production Performance in Highway Projects Using Historical Daily Work Report Data. Journal of Management in Engineering, 36(3), p.04020015. [ID 25]

Lee, C., 2019. Financing method for real estate and infrastructure development using Markowitz's portfolio selection model and the Monte Carlo simulation. Engineering, Construction and Architectural Management. [ID 26]

Liu, J., Jin, F., Xie, Q. and Skitmore, M., 2017. Improving risk assessment in financial feasibility of international engineering projects: A risk driver perspective. International Journal of Project Management, 35(2), pp.204211. [ID 29]

Majchrzak, A., Markus, M.L., Wareham, J. 2016. Designing for digital transformation: lessons for information systems research from the study of ICT and societal challenges. MIS Quarterly, 40 (2), 267-277

Marnewick, C. and Marnewick, A.L., 2019. The demands of industry 4.0 on project teams. IEEE Transactions on Engineering Management. 
Marques, D., de Sá Freire, P., dos Santos, A.V. and Valente, A.M., 2017. Knowledge Management in Project Documentation: a method for optimizing efforts and collective learning. SISTEMAS \& GESTAO, 12(4), pp.436-446. [ID 34]

Martínez-Rojas, M., Marín, N. and Miranda, M.A.V., 2016. An intelligent system for the acquisition and management of information from bill of quantities in building projects. Expert Systems with Applications, 63, pp.284-294. [ID 3]

Matthies, B. and Coners, A., 2018. Double-loop learning in project environments: An implementation approach. Expert Systems with Applications, 96, pp.330-346. [ID 18]

Mazouak, A., Tridane, M. and Belaaouad, S., 2019. Digital management of schools contributions, challenges and constraints case of Morocco. International Journal of Recent Technology and Engineering, 8(3), pp. 28022805. [ID 15]

McAfee A., Brynjolfsson E. 2017. Machine, Platform, Crowd: Harnessing Our Digital Future. WW Norton \& Company.

McDaniel, S.V., 2018. Continuity, Time, and" Artificial Intelligence". Cosmos and History: The Journal of Natural and Social Philosophy, 14(1), pp.105-112.

Moselhi, O., Hegazy, T. and Fazio, P., 1991. Neural networks as tools in construction. Journal of construction engineering and management, 117(4), pp.606-625. [ID 38]

Mueller, R.; Klein, G. 2020. The COVID-19 Pandemic and Project Management Research. Project Management Journal.

Nambisan, S.; Wright, M.; Feldman, M. 2019. The digital transformation of innovation and entrepreneurship: Progress, challenges and key themes. Research Policy. 48(8), 103773.

Niebecker, K., Eager, D. and Kubitza, K., 2008. Improving cross-company project management performance with a collaborative project scorecard. International Journal of Managing Projects in Business. [ID 28]

Niu, Y., Anumba, C. and Lu, W., 2019. Taxonomy and deployment framework for emerging pervasive technologies in construction projects. Journal of Construction Engineering and Management, 145(5), p.04019028. [ID 53]

Oesterreich, T. D. and Teuteberg, F., 2016. Understanding the implications of digitisation and automation in the context of Industry 4.0: A triangulation approach and elements of a research agenda for the construction industry. Computers in industry, 83, 121-139.

Ökmen, Ö. and Öztaş, A., 2015. Scenario based evaluation of a cost risk model through sensitivity analysis. Engineering, Construction and Architectural Management. [ID 47]

Panova, Y. and Hilletofth, P., 2018. Managing supply chain risks and delays in construction project. Industrial Management \& Data Systems. [ID 35]

Project Management Institute (2017). A guide to the Project Management Body of Knowledge (PMBOK guide) (6th ed.). Project Management Institute.

Salah, A. and Moselhi, O., 2015. Contingency modelling for construction projects using fuzzy-set theory. Engineering, Construction and Architectural Management. [ID 8]

Saunders, F.C., Gale, A.W. and Sherry, A.H., 2016. Responding to project uncertainty: Evidence for high reliability practices in large-scale safety-critical projects. International Journal of Project Management, 34(7), pp.1252-1265.

Sebastian, I.M., Ross, J.W., Beath, C., Mocker, M., Moloney, K.G., Fonstad, N.O. 2017. How big old companies navigate digital transformation. MIS Quarterly Executive, 16 (3), 197-213

Seymour, T. and Hussein, S., 2014. The history of project management. International Journal of Management \& Information Systems (IJMIS), 18(4), pp.233-240.

Shahrara, N., Çelik, T. and Gandomi, A.H., 2017. Risk analysis of BOT contracts using soft computing. Journal of Civil Engineering and Management, 23(2), pp.232-240. [ID 44]

Smith, S., 1992. Towards an intelligent planning system. International Journal of Project Management, 10(4), pp.213-218. [ID 54] 
Strojny, J. and Jedrusik, A., 2018. Stakeholder analysis during a reorganization project in local government institutions-key methodological aspects. Marketing and Management of Innovations. [ID 51]

Sun, Y. and Zhang, L., 2015. Balancing public and private stakeholder interests in BOT concessions: minimum revenue guarantee and royalty scheme applied to a water treatment project in China. Journal of construction engineering and management, 141(2), p.04014070. [ID 5]

Tran, D.Q. and Molenaar, K.R., 2015. Risk-based project delivery selection model for highway design and construction. Journal of Construction Engineering and Management, 141(12), p.04015041. [ID 45]

Vanhoucke, M., Demeulemeester, E. and Herroelen, W., 2001. On maximizing the net present value of a project under renewable resource constraints. Management Science, 47(8), pp.1113-1121. [ID 40]

Vial, G. 2019. Understanding digital transformation: A review and a research agenda. The Journal of Strategic Information Systems. 28(2), 118-144

Votto, R., Lee Ho, L. and Berssaneti, F., 2020. Applying and Assessing Performance of Earned Duration Management Control Charts for EPC Project Duration Monitoring. Journal of Construction Engineering and Management, 146(3), p.04020001. [ID 4]

Yoon, J. and Yu, I., 2019. Estimating normal duration of renovation for multistory apartment building considering extension-type renovation projects. Journal of Civil Engineering and Management, 25(2), pp.156-167. [ID 24]

Zhang, J. and Wan, D., 2019. Integrated buffer monitoring and control based on grey neural network. Journal of the Operational Research Society, 70(3), pp.516-529. [ID 30]

Zhang, J., Jia, S. and Diaz, E., 2018. Dynamic monitoring and control of a critical chain project based on phase buffer allocation. Journal of the Operational Research Society, 69(12), pp.1966-1977. [ID 20]

Zhang, L., Dai, G., Zou, X. and Qi, J., 2020. Robustness-based multi-objective optimization for repetitive projects under work continuity uncertainty. Engineering, Construction and Architectural Management. [ID 46] 